\title{
Causes, Risk Factors, and Prevention of Laminitis and Related Claw Lesions
}

\author{
By C. Bergsten
}

Swedish University of Agricultural Sciences, Department of Animal Environment and Health and Swedish Dairy association, Skara, Sweden.

\section{Introduction}

Laminitis is an inflammation of the laminar corium of the hoof wall. In general, the term laminitis is used to describe a systemic disease affecting not only the hooves, but also the general condition of the animal. Researchers believe the inflammation is primarily associated with a dysfunction of the digital vasculatory system that results in hypoxia and malnutrition of the sensitive laminar structure in the hoof wall. The etiology of the circulatory disturbance is not fully understood and there are some possible explanations often related to nutrition, which I will discuss further. Due to mechanical stretching of the attachment between the inner and outer laminar structures of the hoof wall, which has been affected by the inflammation (i.e. laminitis), the claw bone can rotate and or sink inside the hoof. Depending on the severity of the laminitis, the mobility of the claw bone inside the capsule and the counter pressure on the sole from hard floors, the sole corium can be contused and secondary lesions of the sole area can develop (Ossent \& Lisher 1998).

The pathological alterations inside the rigid hoof capsule cause considerable pain and, therefore, results in lameness, which is an animal welfare issue. A United Kingdom survey (Clarkson et al. 1996) revealed a yearly lameness incidence of $55 \%$, of which sole ulcers (40\%) and white line lesions (29\%) were the most prevalent lesions (Murray et al. 1996). Such laminitis-related lesions have a greater economic effect than infectious diseases, for example, (Esslemont \& Spincer 1993), due to severe influence on reproduction and consequently a higher risk for culling (Sprecher et al. 1997). Other common lesions associated with laminitis are: hemorrhages, fissures and abscesses of the white line, sole hemorrhages and double soles, toe ulcers and toe necrosis, and under-running of the heels. Thus, laminitis has a great economic impact on dairy operations, and all over the world dairy producers are moving towards housing cows in intensive, confined conditions. As we understand the causes of laminitis and identify the risk factors better, it is possible to prevent and reduce the effects of the laminitis syndrome.

\section{History}

Laminitis has been described in many species, but is most common in equine and bovine. Although bovine laminitis is most common in dairy cows, it has been reported in all ages and sexes.

The Greeks (Aristotle) associated equine laminitis with indigestion. The Greek name of the disease, Kritiasis, relates to overfeeding of barley. Xenofon noticed the characteristic symptoms, the hooves started to bleed and the horse became recumbent, which were due to pain in the hooves. These are the same symptoms observed in cattle today. During the last centuries, people have also considered that trauma significantly contributes to the disease 
development. Later, toxic or chemical agents through the feedstuff or metastatic spread from infections have also been proposed in the etiology.

Bovine laminitis has a shorter history in the literature than equine. The Swedish Veterinary Journal in 1896 reported, "Inflammation of the claw corium is the most common cause of lameness and the often misshapen claw can be secondarily affected by a purulent process and/or the claw capsule could fall off. The affected animal is useless for work after it has been affected". Rusterholtz disease, i.e. sole ulceration, was described in the 1920s (Rusterholz 1920), but was not associated with laminitis at that time. The first Ph.D. thesis on bovine laminitis was published in the 1960s (Nilsson 1963). It included a thorough description of the symptoms and the pathology, which are still relevant today. Since the same clinical symptoms are also observed in equine laminitis, it is natural that research on the etiology of equine laminitis is used to explain bovine laminitis.

\section{Nutritional influence on laminitis}

In equine experimental models for research, laminitis can easily be provoked by feeding excess quantities of carbohydrates, voluntary or infused. The same methods have not been successfully used in bovine experiments, but challenging diets have provoked more or less laminitis symptoms and claw horn lesions. Researchers have used claw horn lesions as retrospective tools to estimate the influence of various laminitis risk factors (Bergsten 1993, Peterse 1980). Most strikingly Livesey \& Fleming (1984) showed that a separate fed diet with restricted forage resulted in $68 \%$ of the cows with clinical laminitis symptoms at calving, followed by $64 \%$ of them having sole ulcers two to three months afterwards. The control group fed the same amount of concentrates, but provided free access to forage, and it had $8 \%$ with clinical laminitis and $8 \%$ with sole ulcers. The study also showed the association between clinical laminitis and sole ulcers.

In a series of metabolic studies, a higher concentrates-forage ratio (Manson \& Leaver 1987), a higher concentrate amount (Manson \& Leaver 1988a), and a higher dietary protein intake (Manson \& Leaver 1988b), all resulted in higher lameness scores than the controls that were fed less intensive diets. The lesions associated with the lameness were sole ulcers and sole hemorrhages. Sole hemorrhages are considered to be symptom of subclinical laminitis (Greenough 1985).

Peterse et al. (1984) showed in a two-year cross over trial that separate fed concentrates at a higher concentration caused significantly more sole ulcers. In a parallel study with mixed diets, a higherconcentrate ration also resulted in more sole ulcers, although the difference was only significant the second year.

Not only the diet composition, but also the way it is prepared and fed, and the feeding behavior of the animals are important risk factors for laminitis. In a Swedish study in tie-stall herds with separate concentrate feeding, there was no significant association between sole hemorrhage scores and the diets fed. On the other hand, high sole-hemorrhage scores were significantly correlated with feeding concentrates less than four times daily, less time to feed at the manger and feeding concentrates before roughage (Bergsten 1994). These results indicate an interference with the rumen metabolism due to improper feeding management. Recent U.K. studies compared wet and dry forages fed to heifers before calving under the same housing conditions. Wet diets (grass silage DM $19 \%$ ) resulted in significantly more lameness and sole lesions before and after calving than dry diets (straw and concentrates DM 86\%), although other ingredients were comparable.

A concentrate diet fed without enough func- 
tional fibers from the forage results in less chewing, so the cow produces less buffering saliva. It may result in a drop of the rumen $\mathrm{pH}$ and more rapid passage of the ingesta through the alimentary tract. Based on the clinical observations Nordlund (1995) suggested an association between rumen acidosis and laminitis. De Chant et al. (1998) investigated different diets around calving, rumen $\mathrm{pH}$, lameness and sole lesions. More sole lesions were seen two to three months after calving when changing from a high- to a low-fiber diet at calving compared to feeding the same diet before and after calving, or changing from a low- to high-fiber diet. No associations were, however, found between rumen acidosis $(\mathrm{pH}<5.8)$ and sole lesions on an individual basis, or between different diets and acidosis when sampling at 8 and 22 DIM.

It is not clear whether to blame the acidosis itself or the process possibly causing the acidosis. Andersson (1981) infused large amounts of lactic acid directly in the rumen. Despite rumen $\mathrm{pH}$ of 5.0, he observed no symptoms of laminitis or sole lesions. Momcilovic et al. (2000) reduced rumen $\mathrm{pH}$ and increased blood D-lactate by giving high, readily fermentable diets to steers. However, the author did not succeed to provoke laminitis despite some symptoms of discomfort among the calves. Prentice (2000) noticed in an experimental study where steers were overfed starch to reduce rumen $\mathrm{pH}$ that a steer in the study group fed excessive amounts of starch did develop laminitis and sole lesions despite the rumen $\mathrm{pH}$ never going below 6 . Other calves in the experiment group that received less starch, but had lower rumen $\mathrm{pH}$, did not, however, develop laminitis. Thus, the highstarch diet could possibly provoke laminitis and sole lesions without necessarily reducing rumen $\mathrm{pH}$.

Collard et al. (2000) observed the energy balance and health in a dairy herd and found an association between a high-metabolic load and laminitis. Animals with laminitis had a significantly longer and more negative energy balance at 50 and 100 days after calving, and a more severe minimum and total energy deficit than non-laminitis cows. However, in a present trial it was not possible to evaluate cause and effect of the results.

There is evidence that biotin has an important role in the integrity of the hoof wall and thus, most likely in the development of laminitis. The rumen normally produces biotin, but it is probable that an acid environment could alter biotinproducing microorganisms. Biotin supplementation has shown to decrease the incidence of white-line lesions (Midla et al. 1998, Green et al. 2000).

\section{Pathophysiology; missing link behind the nutritional influence}

There are several theories that try to explain the alimentary background to the vasculatory dysfunction that affects the attachment of the hoof bone inside the hoof capsule.

When bovine laminitis was first described in the 1960s (Nilsson 1963), the release of histamine from protein sources in the diet was found to be a reasonable explanation to laminitis. This was also an equine theory of the cause of laminitis from the first $\mathrm{Ph} . \mathrm{D}$. thesis on equine laminitis some decades earlier. Akerblom (1977) demonstrated experimentally that E. coli bacteria enzyme could decarboxylate histidine to histamine in protein-rich grain. It has not, however, been possible to provoke laminitis symptoms by injecting histamine alone in the blood in equines or bovines. However, when steers were first overfed grain followed by a histamine injection, they showed severe laminitis symptoms that lasted for one to 4 days. (Takahashi \& Young 1981)

Another often-adopted explanation of the etiology is that large quantities of endotoxins (toxin released by gram negative bacteria such as $\mathrm{E}$. 
coli) are produced when the gastro-intestinal metabolism is disturbed in an acid environment. The mucous membranes of the gastro-intestinal system normally protect it from absorbing toxins into the blood stream. The mucosa of the bovine fore stomachs are especially fairly resistant while the intestines may be more susceptible. That may explain the higher susceptibility for laminitis in horses than in cattle. But, if the natural barrier is weakened or damaged and if absorbed to the circulatory system, endotoxins are extremely potent and trigger a prostaglandin cascade (chain reaction). An imbalance of the prostaglandins tromboxane and prostacycline is evident, and trombes are produced, which obstruct the small blood vessels (capillaries) of the laminar corium. The blood circulation is locally deteriorated and the result can be compared to a "heart attack" of the feet. The decreased oxygen and nutrient supply damages the corium's horn-producing cells, as has been explained earlier. Elevated levels of endotoxins have been observed in laminitis and trombosis was evident in the corium (Andersson \& Bergman 1980). Researchers have also tried to provoke laminitis by injecting endotoxins into the circulatory system in cattle with results hard to interpret (Mortensen et al.1986).

A more recent hypothesis of equine laminitis has found that laminar enzymes, possibly metalloproteinases, have altered the basal membrane of the laminar corium. Once the junction is affected the corium and horn could be stretched apart from each other, relative to the severity of the lesion (Pollitt 1996). Streptococcus bovis in the equine gut has been suggested as a potential metalloproteinase activator in acute laminitis (Pollitt 1999). This is interesting as background for bovine laminitis, as lacticacid producing bacteria are associated with the disease. So far, this hypothesis has not been reproduced in cattle.

\section{Traumatic effects of laminitis}

Once the claw bone attachment in the horn capsule has been disrupted the claw is at risk for further damage. Due to the severity of the disruption, loading and biomechanics, the claw bone sinks and/or rotates more or less permanently inside the horn capsule and the prominent parts of the bone contuse the adjacent sole corium (Ossent \& Lisher 1998). The contusion or pinching of the corium depends on the counter pressure and causes a secondary inflammation of the sole corium with edema and hemorrhaging. The hemorrhages from the corium will be incorporated into the growing horn and will be visible at trimming. The lesions on the sole can be compared to a print of the bone where it hits the sole. The most commonly affected regions are the rear part of the claw bone, recognized as the "typical" sole-ulcer site, the junction of the sole and white line of the posterior outer wall, and the toe area. The time lapse from the initial insult until the hemorrhage can be detected depends on the growth rate of the sole and the sole thickness.

As it takes two to three months until the hoof lesions are visible, the close relationship between laminitis and hoof lesions has not always been well understood. Sometimes sole hemorrhages are misinterpreted as stone bruises. Changes of the bone position inside the claw capsule also affect the grooving wall. You can see a horizontal break point of the wall, also known as a hardship groove or laminitic ring, after each disruption of horn growth (Greenough 1985). The newly produced wall horn of the upper part follows the new position of the bone while the lower part of the wall, beneath the groove, reflects the position of the bone before the laminitis period. Thus, the rotated bone inside the capsule is reflected as a concavity of the wall outside. In claws from slaughtered cows with chronic recurrent laminitis, a concavity of the dorsal wall was associated with a permanent ro- 
tation of the claw bone and protrusion of the corium (Kehler \& Sohrt 2000).

\section{Claw conformation and weight distribution}

The weight distribution between the inner and outer claws, of the sole and wall area within each claw, and the shock absorbing mechanisms in the foot are related to the trauma of the sole corium towards the floor. At normal gait the heel bulbs and the outer wall will make the first contact with the ground and the weight will be distributed equally between the outer and inner claw. While the soft bulbs reduce the shock of the rear part of the claws the weight on the wall will successfully be transferred on the sole due to slight splaying of the claws. Inside the capsule, the suspensory apparatus made of collagen tissue and the digital cushions made of fat pads protect the sole corium.

Sole lesions are rarely seen in free-ranged cattle on a soft foundation and their soles are concave from the outer wall to the central part. Tranter \& Morris (1992) found that when animals were moved from pasture to hard floors during lactation, the rear outer claw's natural sole concavity disappeared while the inner claw's concavity remained. This is a common observation from claws that have been on concrete for a while. A vicious cycle starts, which increases sole growth and wear in the overloaded area and causes asymmetric claws. Asymmetric rear claws, where the outer claw is larger than the inner claw and the sole is flat, is the most common site for sole lesions. Consequently, if the natural concave shape of the claws has disappeared, and the sole is flat or convex, the sole will take more weight than the wall initially, and shock absorption will rely more on the suspensory apparatus and the digital cushion. Lischer et al. (2000) compared normal feet and feet affected with sole ulcers from slaughtered cows. Claws with sole ulcers had a more sunken claw bone, and more compressed soft tissues and less fat in the cushions.

\section{Risk factors for laminitis other than diet Changes around calving}

Often, dairy cows experience many changes around calving, such as being introduced to lactation diet and new housing facilities. First-time heifers also experience these changes and they are thus presumed to be more susceptible than pluriparous animals. Vermunt \& Greenough (1996) observed sole hemorrhages in Holstein heifers several months before calving and the lesions were more severe in housed animals than those in a dry lot. Some of them developed sole ulcers shortly after calving and the lesions of the all the animals were reduced at two months after calving. Also, Logue et al. (2000) scored sole lesions in heifers several months before calving, and white-line lesions peaked two months after calving and sole hemorrhages four months after calving. In my study (Bergsten \& Frank 1996a), 60 heifers in early pregnancy were tied on either concrete floors or on rubber mats and were challenged with high- or low-concentrate diets. Sole-hemorrhage scores were generally low and no differences were found between groups. The same animals were grazed during the summer, regrouped, and housed on concrete floors or rubber mats in the fall. They were allocated to either a high- or a low-concentrate diet (Bergsten \& Frank 1996b). All claws were scored for sole hemorrhages at trimming two weeks before and again 14 weeks after calving. The animals on the concrete floors had significantly higher scores than those on rubber mats. The combination of highconcentrate feeding and concrete floors resulted in significantly more sole hemorrhages than the low-concentrate diet and rubber mats. Webster (2000) found similar results where animals housed in cubicles with concrete floors had significantly more sole lesions than those 
housed on straw yards, independent of diets. The lesions reached their highest values about eight weeks after calving.

In the same series of my experiments, another group of heifers was tied up on concrete floors during the winter before calving in spring. The presence of sole hemorrhages was compared to the sole-hemorrhage scores of heifers calving on concrete floors the previous autumn with the same diets. The spring-calvers had higher scores than the autumn-calvers before calving, but significantly lower scores after calving (Bergsten \& Frank 1996b). The results were interpreted as spring-calving heifers had a longer period to adapt to concrete floors before calving, compared to the autumn-calving animals who came from pasture just a few weeks before calving. It could be concluded from the experiments above that calving per se, and environmental and management changes before calving were the main contributing factors for subclinical laminitis.

\section{Floors and exercise}

As revealed in the experiments above, hard floors increase the risk of subclinical laminitis. Also in a field study, animals on concrete floors had higher sole-hemorrhage scores than those tied on rubber mats (Bergsten 1994). When cows tied on rubber mats were compared to cows in cubicles with rubber mats and concrete slatted floors, significantly more white-line hemorrhages were found in the latter group (Bergsten and Herlin 1996). Danish studies came to the same conclusion that tied animals on rubber mats had less hoof lesions than those in loose housing (Thysen 1987). These findings are in accordance with the observations that white-line lesions and trauma of the wall are seen less seldom in tied than in free moving cattle on hard floors (Rowlands et al. 1983). A tearing of the hemorrhagic weakened wall, as when the animal turns around, can cause a fis- sure between wall and sole in the white line and a white-line abscess.

More recent studies (Jungbluth et al. 2003) found clairy cows in a free stall barn on soft slatted rubber mats to have significantly less laminitis related hoff lesions than those walking on traditional concrete slatted floors.

\section{Cow comfort and behavior}

With a comfortable environment, dairy cows will lie down 12 to 15 hours a day and most often when ruminating. Comfortable stalls mean soft bedding and enough space for rising and lying down. In uncomfortable stalls, cows often stand half in the cubicles with their rear feet on the alley. A longer standing time increases the loading and exposure to unhygienic materials, particularly for the rear feet. Leonard et al. (1994) illustrated the effect of prolonged standing due to uncomfortable stalls. Heifers were introduced either to comfortable cubicles equipped with rubber mats and open dividers, allowing better space for rising and lying down; or to concrete-based cubicles without bedding, with dividers more closed on the sides, and without lunge space. Researchers assessed lying time and sole-hemorrhage scores before and after the cows had been introduced to the cubicles at calving. At calving, heifers were lying significantly longer in the more comfortable stalls. Two months after calving, the animals in the uncomfortable stalls had significantly more sole hemorrhages. The sole hemorrhages thus reflected the longer standing time due to poor comfort that took place 2 months earlier.

The animals' behavior when being fed can also influence the development of laminitis. Leonard et al. (1996) scored the interaction behavior in animals where the feed space at the manger was reduced. The sole-hemorrhage scores were significantly higher in the animals with a high interaction score than in those with low interactions. The study concluded that 
competing for food at the manger could provoke interactions between animals resulting in sole hemorrhages. On the other hand, the behavior of a lame cow will be affected. Manson (1989) found that lame cows lost rank in the herd, ate for a shorter time, consumed less dry matter, and had a higher eating rate than healthy herd mates.

\section{Claw trimming}

Claw trimming has proved to reduce lameness associated with laminitis when correctly performed. Manson \& Leaver (1988b) showed that trimming the feet before calving resulted in fewer lame cows than when the feet were not trimmed. Preliminary results from a Swedish study (Manske et al. 2001) showed almost twice as many sole ulcers in animals trimmed only once each year compared to those trimmed twice. One function of claw of trimming is to detect lesions at an early stage before clinical symptoms or severe lesions develop. The other part is to prevent lesions by correcting the loading. Distl \& Mair (1990) showed that when the distribution of weight between the claws is unequal and the sole bears too much weight, there is greater risk for sole lesions. When the feet are trimmed, the weight is more equally distributed between and within the claws. However, it is more difficult to equalize the weight distribution in cows with excessive wear, i.e. cows in cubicles on abrasive concrete floors.

\section{Preventing laminitis, claw lesions and lameness}

Laminitis with secondary claw lesions is frequently a herd problem. As with other production diseases, laminitis is multifactorial and management decisions are critical to reduce most laminitis risk factors. Thus, the possibility to prevent laminitis increases if farmers or managers understand and are aware of the problem and its consequences. There will be larger herds, and breeding for higher milk yield will continue. Laminitis-related lesions have shown to have a high heritability (Manske 2001, personal communication ). It would be beneficial to include lameness and claw lesion records in breeding programs in the future. Such records can also help dairy producers monitor herd problems and make decisions to improve hoof health, and to evaluate the effects of a preventative protocol (Bergsten 2000)

\section{Diet and feeding management}

Based on experimental and epidemiological studies it is evident that diets and feeding management are of great importance for laminitis. All measures to increase optimal rumination and reduce the risk for acidosis should be made (Nordlund 1995). Precautions concerning feeding management include: a gradual adjustment to a lactation diet, use feeding routines that stimulate natural digestion and feed well-balanced diets with enough functional fiber to promote rumination.

Even when following up-to-date recommendations, lameness problems can occur in a herd. Troubleshooting should include not only the diets that are offered, but also how the diet is prepared and what actually is consumed (Shaver, 2000). Over mixing total mixed rations can reduce the mechanical efficiency of fiber in the rumen. The same phenomena can occur when cows sort feed at the manger. If there are reasons to believe that trace elements, minerals and biotin levels are insufficient, one should supplement these items. Biotin can be supplemented at $20 \mathrm{mg}$ per animal per day. However, due to the rate of horn growth, do not expect results from the supplementation until months afterwards (Seymour 1998).

\section{Housing and cow comfort}

The dairy industry's awareness of concrete floors' negative influence on claw health has in- 
creased during recent years. Primary advice is to provide a long enough adjustment period, especially if moving animals from pasture or deep bedding to harder floors. Changing ground surface just before calving should be avoided, and this adaptation should be made at least two months before calving.

Rubber mats have proved to be a durable material that reduces the risk of laminitis. Using rubber mats on concrete areas is seen more and more as a measure to reduce claw-floor challenges. Many farms put rubber on the floors along feed bunks, in holding pens and on the alleyways to the milking parlor. This is a good prevention, but could, depending on cleaning system, interfere with the hygiene. To get a softer and more hygienic environment for the claws, and thus prevent problems, a specific type of feed stalls have been constructed in Swedish cubicles barns. The individual feed stalls are $1.60 \mathrm{~m}$ long, on a $0.2 \mathrm{~m}$ elevated platform and use dividers between each cow $(0.80$ $\mathrm{m}$ distance). The manger is elevated $20-40 \mathrm{~cm}$ above the foot level to make eating more comfortable. The cow can stand with all four feet on the rubber mat and still deposit manure on the alley behind the platform. With feed stalls the alleys can be scraped or flushed more frequently without disturbing the animals when they are eating, unlike in traditional systems. Moreover, feed stalls reduce stress and social interactions in the herd by improving cow traffic and giving continuous access to food. Using cubicles with enough lunge space and soft bedding to improve lying comfort is noticed more and more. Optimal stall comfort will reduce involuntary standing and exposure to concrete. Still, increased walking distances, prolonged feeding time, and increased time in holding pens waiting for milking reduces the time available for lying down, and thus increases the load on the feet and risk for lesions.

\section{Conclusions}

Lameness is an increasing problem associated with higher production, more intensive feeding and confined conditions. Laminitis is a complicated disease of which the origin is not clearly understood. It results in claw horn lesions that highly affect the cow's well being, production and longevity. Laminitis can be avoided with physiological digestion, and secondary claw lesions can be avoided by accurate and physiological loading.

\section{Literature}

Andersson L: An attempt to induce laminitis in cows by intraruminal infusion of lactic acid. Acta Vet Scand, 1981, 31, 140-142.

Andersson L, Bergman A: Pathology of bovine laminitis especially as regards vascular lesions. Acta Vet Scand, 1980, 21, 559-566.

Bergsten C: A photometric method for recording hoof diseases in cattle, with special reference to haemorrhages of the sole. Acta Vet Scand, 1993, 34, 281-286.

Bergsten C: Haemorrhages of the sole horn of dairy cows as a retrospective indicator of laminitis: an epidemiological study. Acta Vet Scand, 1994, 35, 55-66.

Bergsten C: Work shop report about the documentation of claw diseases; Part 2, Descriptive nomenclature and scoring of foot lesions at hoof trimming,. In: C.M. Mortellaro, L. De Vecchis and A. Brizzi (Editors), Int. Symp. Disorders Ruminant Digit \& Int. Conf. on Bov. Lameness. New team, Parma 2000, pp. 226-229.

Bergsten C, Frank B: Sole haemorrhages in tied heifers in early gestation as an indicator of laminitis: Effects of diet and flooring. Acta Vet Scand, 1996a, 37, 375-382.

Bergsten C, Frank B: Sole haemorrhages in tied primiparous cows as an indicator of periparturient laminitis: Effects of diet, flooring and season. Acta Vet Scand, 1996b, 37, 383-394.

Bergsten C, Herlin AH: Sole haemorrhages and heel horn erosion in dairy cows: The influence of housing system on their prevalence and severity. Acta Vet Scand, 1996, 37, 395-408.

Bergsten C, Hultgren J, Manske T: Claw traits and foot lesions in Swedish dairy cows in relation to trimming interval and housing. A preliminary re- 
port. In: P. Ossent and C. Lischer (Editors), 10th Int. Symp. Disorders Ruminant Digit. University of Zurich Dept. Vet Surgery, Lucerne 1998.

Clarkson MJ. et al: Incidence and prevalence of lameness in dairy cattle. Vet Rec, 1996, 138, 563567.

Collard BL, Boettcher PJ, Dekkers JC, Petitclerc D, Schaeffer LR: Relationships between energy balance and health traits of dairy cattle in early lactation. J Dairy Sci, 2000, 83, 2683-90.

DeChant GM et al.: Effect of transition energy and fiber levels on subclinical laminitis and rumen acidosis in Holstein cows in Florida. In: E.I. Williams (Editor), Thirty first conf.. AABP, Spokane, 1998, pp. 186.

Distl O, Mair A: Pedobarometric forces at the sole/floor interface. In: R.D. Murray (Editor), Update in Cattle Lameness, VI Int Symp Disorders Ruminant Digit. Brit Cattle Vet Ass, Liverpool, UK 1990, pp. 143-162.

Esslemont RJ, Spincer L: The incidence and costs of diseases in dairy herds, Univ of Reading, Reading 1993.

Green LE, Hedges VJ, O'Callaghan C, Blowey RW, Packington A: Biotin supplementation to dairy cows - Multivariate analysis of the prospective longitudinal study. In: C.M. Mortellaro, L. De Vecchis and A. Brizzi (Editors), Int. Symp. Disorders Ruminant Digit \& Int. Conf. on Bov. Lameness. New team, Parma, 2000, pp. 305-307.

Greenough PR: The subclinical laminitis syndrome. Bov. Pract. 1985, 20, 144-149.

Jungbluth $T$ et al.: Soft walking on loose housing systems for dairy cows. In: Jann K (ed): Fifth Int. Dairy Housing Proc. Conf. ASAE Publications no. 701 P0203, 2003, 171-177.

Kehler W, Sohrt JT: Special considerations of laminitis lesions for claw trimming (hind claw of Holstein-Friesian cows). In: C.M. Mortellaro, L. De Vecchis and A. Brizzi (Editors), Int. Symp. Disorders Ruminant Digit \& Int. Conf. on Bov. Lameness. New team, Parma, 2000, pp. 258-259.

Leonard FC, Oconnell J, Ofarrell K: Effect of Different Housing Conditions on Behavior and Foot Lesions in Friesian Heifers. Vet Rec, 1994, 134, 490-494.

Leonard FC, Oconnell JM, Ofarrell KJ: Effect of overcrowding on claw health in first-calved Friesian heifers. Brit. Vet. J., 1996, 152, 459-472.

Lischer CJ, Ossent P, Räber M, Greyer H: The significance of the suspensory mechanism of the third phalanx and its fat bodies in the pathogene- sis of sole ulcers in cattle, Part I: macroscopic findings. In: C.M. Mortellaro, L. De Vecchis and A. Brizzi (Editors), Int. Symp. Disorders Ruminant Digit \& Int. Conf. on Bov. Lameness. New team, Parma, 2000, pp. 222-225.

Livesey CT, Fleming FL: Nutritional influences on laminitis, sole ulcer and bruised sole in Friesian cows. Vet Rec, 1984, 114, 510-512.

Logue D, Leach KA, Brocklehurst S, Offer JE: Effect of diet on lesion development from birth up to the end of first lactation. In: C.M. Mortellaro, L. De Vecchis and A. Brizzi (Editors), Int. Symp. Disorders Ruminant Digit \& Int. Conf. on Bov. Lameness. New team, Parma, 2000, pp. 327-332.

Manske, T, Hultgren J, Bergsten C: The effects of claw trimming on hoof health of Swedish dairy cattle. Prev. Vet. Med. 2001, 54, 113-127.

Manson FJ: Lameness and cattle welfare - a case study, Technical report. Dairy Research Unit, Univ. Wales 1989.

Manson FJ, Leaver JD: Effect of Concentrate to Silage Ratio and Hoof Trimming on Lameness in Dairy-Cows. Anim. Prod., 1987, 44, 469-469.

Manson FJ, Leaver JD: The influence of concentrate amount on locomotion and clinical lameness in dairy cattle. Anim. Prod., 1988a, 47, 185-190.

Manson FJ, Leaver JD: The influence of dietary protein intake and of hoof trimming on lameness in dairy cattle. Anim. Prod., 1988b, 47, 191-199.

Midla LT, Hoblet KH, Weiss WP, Moeschberger ML: Supplemental dietary biotin for prevention of lesions associated with aseptic subclinical laminitis (pododermatitis aseptica diffusa) in primiparous cows. Am J Vet Res, 1998, 59, 733-8.

Momcilovic D, Herbein JH, Whittier WD, Polan CE: Metabolic alterations associated with an attempt to induce laminitis in dairy calves. J Dairy Sci, 2000, 83, 518-25.

Mortensen K, Hesselholt M, Basse A: Pathogenesis of bovine laminitis (diffuse aseptic pododermatitis). Experimental models. In: P.J. Hartigan and M.L. Monoghan (Editors), 4th World Congress on Dis of Cattle. Irish Cattle Vet Ass, Dublin, Ireland, 1986, pp. 1025-1030.

Murray RD et al.: Epidemiology of lameness in dairy cattle: Description and analysis of foot lesions. Vet Rec, 1996, 138, 586-591.

Nilsson SA: Clinical,morphological and experimental studies of laminitis in cattle. Acta Vet Scand, 1993, 4, sup 1: pp 304.

Nordlund: Herd-based rumenocentesis: A clinical approach to the diagnosis of subacute rumen aci- 
dosis. The Compendium (August): 1995, 48-56.

Ossent P, Lisher CJ: Bovine laminitis: the lesions and their pathogenesis. In Practice, 1998, 20, 415427.

Peterse DJ: Judgement of bovine claws by the occurrence of sole lesions. PhD Thesis, Utrecht 1980.

Peterse DJ, Korver S, Oldenbroek JK, Talmon FP: Relationship between levels of concentrate feeding and incidence of sole ulcers in dairy cattle. Vet Rec, 1984, 115, 629-630.

Pollitt CC: Basement membrane pathology: a feature of acute equine laminitis. Equine Vet J, 1996, 28, 38-46.

Pollitt CC: Equine laminitis: A revised pathophysiology., Am Ass Eq Pract, 1999, pp. 188-192.

Prentice DL: Ionophores: Modes of action and use in the prevention of ruminal acidosis and subacute ruminal acidosis. MS thesis Thesis, Univ. Wisconsin-Madison 2000.

Rowlands GJ, Russell AM, Williams LA: Effects of season, herd size, management system and veterinary practice on the lameness incidence in dairy cattle. Vet Rec, 1983, 113, 441-445.

Rusterholz A: Das spezifisch-traumatische Klauensohlengeschwür des Rindes. Schweizer Archiv für Tierheilkunde, 1920, 62, 505-525.

Seymour $W$ : Role of biotin in ruminant nutrition examined, Feedstuffs, 1998, pp. 6.

Shaver $R D$ : Feed delivery and bunk management aspects of laminitis in dairy herds fed total mixed rations. In: C.M. Mortellaro, L. De Vecchis and A. Brizzi (Editors), International Symposium on
Disorders of the Ruminant Digit \& International Conference on Bovine Lameness. New team, Parma, 2000, pp. 70-77.

Sprecher DJ, Hostetler DE, Kaneene JB: A lameness scoring system that uses posture and gait to predict dairy cattle reproductive performance. Theriogenology, 1997, 47, 1179-1187.

Takahashi K, Young BA: Effects of grain over-feeding and histamine injection on physiological responses related to acute bovine laminitis. Jap J Vet Sci, 1981, 43, 375-385.

Thysen I: Foot and leg disorders in dairy cattle in different housing systems. In: H.K. Wierenga and D.J. Peterse (Editors), Cattle housing systems, lameness and behaviour. Martinus Nijhoff Publishers, Dordrecht, 1987, pp. 166-178.

Tranter WP, Morris RS: Hoof growth and wear in pasture-fed dairy-cattle. N Z Vet J, 1992, 40, 8996.

Webster AJF: Effects of wet v. dry feeding and housing type on the pathogenesisof claw horn disruption in first-lactation dairy cattle. In: C.M. Mortellaro, L. De Vecchis and A. Brizzi (Editors), International Int. Symp. Disorders Ruminant Digit \& Int. Conf. on Bov. Lameness. New team, Parma, 2000, pp. 340-345.

Vermunt JJ, Greenough PR: Sole haemorrhages in dairy heifers managed under different underfoot and environmental conditions. Brit Vet J, 1996, 152, 57-73.

Akerblom E: Fång - histamine - rheumatic symptoms. Svensk Vet ti, 1977, 29, 5-10.

Contribution to 11. International Conference on Production Diseases in Farm Animals 12-16 August 2001, KVL, Frederiksberg, Denmark.

Reprints may be obtained from: Christer Bergsten, Department of Animal Environment and Health Swedish University of Agricultural Sciences, Skara, Sweden. 